\title{
Rhizosphere metagenomics of mine tailings colonizing plants: assembling and selecting synthetic bacterial communities to enhance in situ bioremediation
}

Miguel Romero ${ }^{1,2,3}$, Diana Gallego ${ }^{1,2 木}$, Jazmin Blaz ${ }^{1,2}$, Arely Lechuga ${ }^{1,2}$, José F. Martínez ${ }^{4}$ Hugo R. Barajas ${ }^{1,2}$, Corina Hayano-Kanashiro ${ }^{5}$, Mariana Peimbert ${ }^{6}$, Rocío Cruz-Ortega ${ }^{7}$, Francisco E. Molina-Freaner ${ }^{3}$, and Luis D. Alcaraz ${ }^{1,2 *}$

${ }^{1}$ Departamento de Biología Celular, Facultad de Ciencias, Universidad Nacional Autónoma de México. 04510 Coyoacán, Ciudad de México, México.

${ }^{2}$ Laboratorio Nacional de Ciencias de la Sostenibilidad (LANCIS), Instituto de Ecología, Universidad Nacional Autónoma de México. 04510 Coyoacán, Ciudad de México, México.

3 Posgrado en Ciencias Biológicas, Unidad de Posgrado, Edificio 1er piso, Ciudad Universitaria. Universidad Nacional Autónoma de México. 04510. Ciudad de México.

${ }^{4}$ Departamento de Ecología de la Biodiversidad, Instituto de Ecología, Universidad Nacional Autónoma de México. 04510 Coyoacán, Ciudad de México, México.

${ }^{5}$ Departamento de Investigaciones Científicas y Tecnológicas, Universidad de Sonora, Hermosillo, México.

6 Departamento de Ciencias Naturales, Universidad Autónoma Metropolitana, Unidad Cuajimalpa. 05348, Cuajimalpa, Ciudad de México, México.

7 Departamento de Ecología Funcional, Instituto de Ecología, Universidad Nacional Autónoma de México. 04510 Coyoacán, Ciudad de México, México.

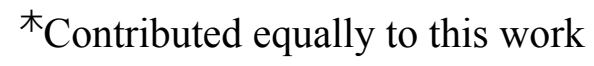

*Correspondence:

Luis D. Alcaraz

lalcaraz@,ciencias.unam.mx

Keywords: Metagenomics, rhizosphere metagenome, synthetic bacterial community, mine tailing, phytostabilization 


\section{Abstract}

Mine tailings phytostabilization has been proposed as a bioremediation strategy to constrain the contaminants dispersion using plants to limit the effects of erosion. Rhizospheric bacteria impact plant health and facilitate plant establishment through their metabolic functions, which could be relevant in bioremediation strategies. We studied both culturable and metagenomic diversity or rhizospheric bacteria of mine tailings colonizing plants of an abandoned mine operation in Nacozari de García, Sonora, Mexico. Diversity was described through amplification of the 16S rRNA gene and whole metagenome shotgun sequencing of both environmental and cultured rhizosphere associated microbes. The culturable bacteria were assembled in a synthetic community (SC; 235 bacteria genera). Subsequently, we performed an experimental evolution setup with the SC, selecting for heavy metal resistance, microbial competition, and the ability for growing in plant-derived nutrient sources. The selection experiment show that bacteria diversity decreases from the environmental culturefree microbiomes to the mine tailings rhizospheres and the experimental evolution outcome: the synthetic community (FSC; 43 bacteria genera). The rhizosphere communities shifted from the dominance of Actinobacteria in their environment to Proteobacteria in the cultivated consortia and the synthetic communities. Both environmental and cultured metagenomes contained plant-growth promotion, heavy-metal homeostasis, and antibiotic resistance predicted genes. The FSC included predicted proteins related to plant-growth promotion such as siderophore production and plant hormone regulation proteins. We reconstructed a metagenome assembled genomic sequence named Enterobacter sp., Nacozari. The recovered Enterobacter sp. Nacozari, have predicted coding genes for direct and indirect plant growth promotion along with adhesion and oxidative stress-related proteins. The metabolic potential of the FSC presents promising features that might make it useful for plant-growth promotion in tailored phytostabilization strategies for the abandoned mine-tailings of Nacozari.

Keywords:

phytostabilization, mine tailings, rhizosphere, metagenomics, synthetic bacterial community 


\section{Introduction}

Unconfined mine tailings are harsh environments for plant colonization due to their conditions such as extreme $\mathrm{pH}$, high concentrations of heavy metals, reduced water retention capacity, and autotrophic bacteria. In the absence of plants that reduce erosion, in arid and semi-arid climate regions these toxic wastes are dispersed through water and air currents that are dispersed to adjacent areas and are associated with human diseases (Meza-Figueroa et al.,2009; Nriagu 1988). Mine reclamation should be the ideal condition at the end of the mine operation, however, there is no regulation for old abandoned mines in multiple developing countries (Favas et al.,2018). Open mining reclamation strategies include phytostabilization which aims to reduce pollutants motility through plant coverage, ideally a plant community able to immobilize the metals in the roots, low shoot translocation, while recruiting heterotrophic bacteria and stabilizing the wasteland (Ali, Khan \& Sajad, 2013).

A mine bioremediation in situ strategy known as phytostabilization, which prevent the exposure of mine waste into the environment, due to the use of local plants to prevent erosion through root consolidation of the mine tailings (Mendez \& Maier 2008). Additionally, the plant roots exudates along the bacteria rhizosphere community precipitate heavy metals (Santos et al.,2017). A plant species is a candidate for phytostabilization of heavy metals if they are not translocated to shoots, keeping most of it precipitated or root-accumulated, thus preventing incorporation of heavy metals into trophic networks (i.e., cattle foraging) (Santos et al.,2017). In previous work, a spontaneously plant community colonization of an abandoned mine operation (ca. 1949) in north-western Mexico (Nacozari de García, Sonora, Mexico) was described (Santos et al.,2017). It was possible to identify plant species with bioremediation potential for the Nacozari mine tailings: Acacia farnesiana, Brickellia coulteri, Baccharis sarothroides, and Gnaphalium leucocephalum (Santos et al.,2017). Here we are following up that work and studying the microbial communities that could lead or restrict plant establishment in this location.

Previous work, has demonstrated that bacteria can be trained, as it has been done in the ongoing long term evolution experiment (LTEE), in which 12 Escherichia coli cell lines have been cultured in liquid glucose-limited medium and put through a bottleneck of $1 \%$ of the whole population in each serial pass into fresh medium each 24 hours. After the first 2,000 
generations, the populations presented a higher fitness than the original cell lines growing in glucose-limited conditions (Lensky \& Travisano, 1994), the experiment is now over 60,000 generations and it has been suggested that the fitness peak is not yet achieved (Good et al.,2017). Bacterial communities harbor different interactions such as cooperation, inhibition, and competition, while some members of the community might remain neutral and avoid all of the above resulting in community-intrinsic properties or properties of bacteria that are shown only in community level (Madsen et al.,2018). It has been shown that if a new member is introduced in the community, it will likely be sensitive to the antagonism effectors of the original members (Pérez-Gutiérrez et al., 2013). The build of synthetic communities is the scaling up of experimental evolution from single or two species interaction to integrating emergent member and molecular interactions of complex model systems, yet culturable and thus capable of testing experimentally the models, from genome interactions to predictable outputs (Cairns et al., 2018; Zomorrodi \& Segrè 2016).

Plant-microbe interactions are critical for plant establishment, nutrient acquisition, and microbe interactions including neutral, parasitic, or mutualistic interactions affecting plants health (Bulgarelli et al.,2013). The plant roots-microbe interactions are essential for the establishment of the plant microbiome, some members of the bacteria community are capable of inducing plant-growth promotion (PGPB). PGPB comprehends multiple strategies, like nitrogen fixation, phosphate acquisition, plant-hormone production. For example, phosphate solubilization through the synthesis of organic acids and the production of phytases, mediated by the PqqBCDEFG proteins and AppA/A2, respectively (Liu et al.,1992; Rodriguez et al.,1999). In addition, rhizospheric bacteria can also modulate plant hormone concentrations by the synthesis of indole-3-acetic acid (IAA) with the enzyme phenylpyruvate decarboxylase, thus promoting root elongation (Spaepen et al.,2007) or by the consumption of 1-aminocyclopropane-1-carboxylate (ACC), an ethylene precursor, through the enzyme ACC deaminase, which maintain healthy ethylene concentrations in plant tissue (Glick et al.,1998). It has also been observed that ethylene pathways could help prevent salinity stress in plants, via bacterial production of ethylene precursors like 2-keto-4-methylthiobutyric acid (KMBA) (de Zélicourt, et al.,2018). Bacteria are also capable of immobilizing heavy metals through biosorption and dissimilatory reduction (Valls \& De Lorenzo, 2002) while modulating their micronutrient concentration homeostasis through cation efflux pumps (Nies, 1999). Biofertilizers have been widely proposed as a sustainable and eco-friendly approach to promote plant growth (Bhardwaj et al.,2014). However, single species biofertilizers lack the community interactions described before, and it has been reported that simple communities ( 
$\leq 3$ bacteria species) synergistic effects could lead to effective bioaugmentation and improvements in plant growth (Mansotra et al.,2015). Therefore, the design of biofertilizers inoculum should try to include entire communities. The design of synthetic bacterial communities is made with the rationale of harnessing the microbiome influence in the host phenotypes, and it is a newly developing field in the study of plant-microbe interactions (Herrera Paredes et al.,2018).

In this study, we describe both culturable and culture-free microbiomes from Nacozari minetailing rhizosphere microbe communities through 16S rRNA gene amplicons and whole shotgun metagenomic sequencing. We are introducing a mix of rhizospheric culturable strains into a synthetic community (SC), and then performing an experimental evolution setup looking for a culturable microbial community capable of surviving under mine-tailing conditions, also selected to depend solely on carbon sources derived from roots, and interact with the other bacteria community members (Figure 1).
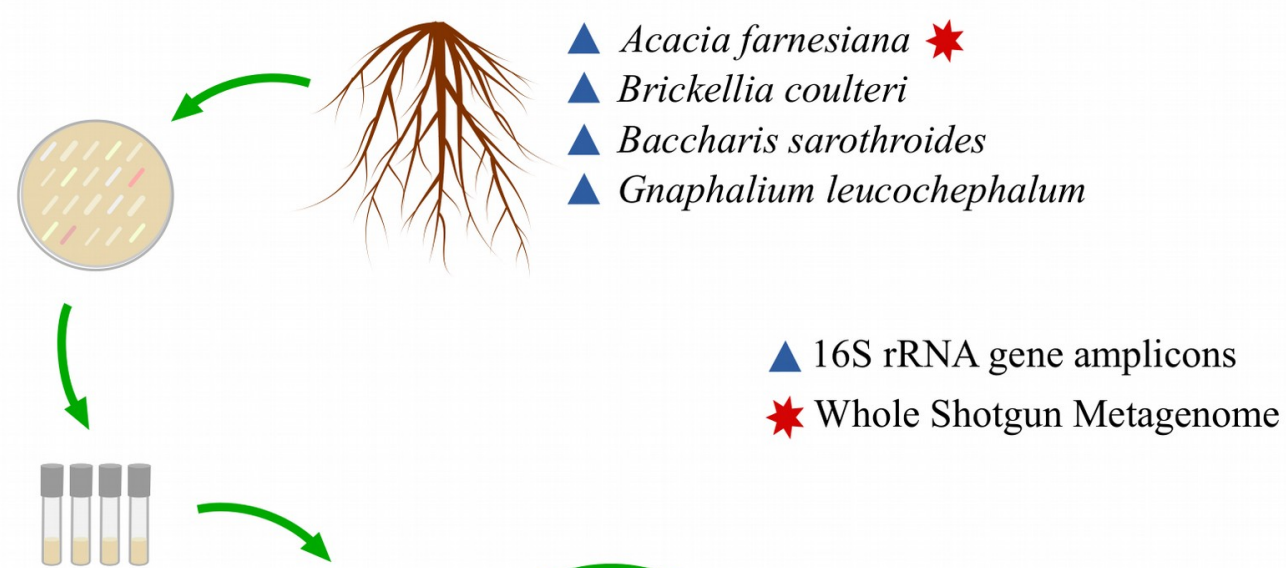

Individual growth

(235 strains)

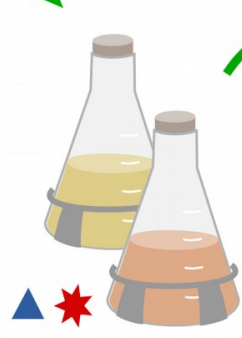

Synthetic community(SC)
$22 \mathrm{x}$ medium + mine tailing

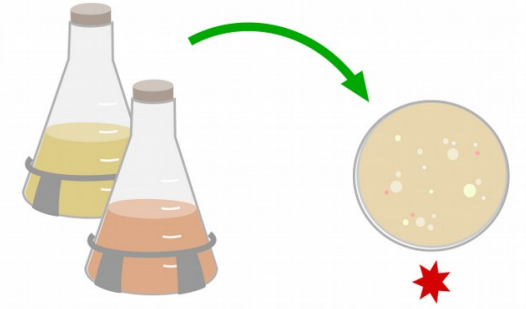

Final Synthetic community (FSC)

Figure 1. Overview of this work. In situ biodiversity of the Nacozari mine tailings was described both by $16 \mathrm{~S}$ rRNA gene amplicons and shotgun sequencing. A total of 235 rhizosphere-derived bacterial strains were selected to assembly the synthetic community 
(SC). The SC was cultured in plant derived culture media or complex sugars, with an inhibiting mine tailings concentration for heavy-metal unadapted bacteria (see Material and Methods). Twenty-two serial passes of the SC were performed each 48 hours, the last serial pass is known as final synthetic community (FSC). The metabolic and taxonomic profiles were predicted for the SC and the FSC through the analysis of their shotgun metagenomes.

\section{Material and Methods}

\section{Sampling}

The town of Nacozari de García, Sonora is a mining district in northern Mexico $\left(30^{\circ} 22^{\prime} 2.4^{\prime \prime} \mathrm{N}, 109^{\circ} 41^{\prime} 38^{\prime \prime} \mathrm{O}\right)$, it has a semi-arid climate with an annual mean temperature of $19.6^{\circ} \mathrm{C}$ and annual mean precipitation of $490 \mathrm{~mm}$. The mine-tailing dam which lies adjacent to the residential zone (Supplementary Figure 1) contains quartz (SiO2), gypsum $(\mathrm{CaSO} 4 \mathrm{H} 2 \mathrm{O})$, lepidocrocite $(\mathrm{FeO}[\mathrm{OH}])$ and copper sulfate (CuSO4, Romero et al., 2008). Mine tailing mean $\mathrm{pH}$ is $3.8 \pm 0.3$, and its average electrical conductivity is $340.1 \pm 2 \mu \mathrm{S} / \mathrm{cm}$ (Meza-Figueroa et al., 2009). Root samples for amplicon and metagenomic DNA sequencing were collected on December, 1st, 2015, between 11:09 AM and 2:19 PM, for each plant species of A. farnesiana (Afp1), B. coulteri (Bc), B. sarothroides (Bs), and G. leucocephalum (Gl) growing on mine tailing, including an additional sample from an A. farnesiana plant growing in a secondary vegetation patch (Afp2; Supplementary Figure S1). Samples for metagenomic DNA extractions were stored in $50 \mathrm{ml}$ sterile conical tubes and immediately stored in liquid nitrogen then stored in a freezer at $-80{ }^{\circ} \mathrm{C}$ until DNA extraction. Sampling for microbiological cultures were collected on March 29th, 2016, from 7:26 AM to 8:20 PM. Duplicated root samples from plants species A. farnesiana (Afp1-CC), B. coulteri (Bc-CC), B. sarothroides (Bs-CC), and G. leucocephalum (Gl-CC) from the main tailing vegetation patch and an additional sample from an A. farnesiana (Afp2-CC) plant growing in a secondary vegetation patch (Supplementary Figure S1), were collected as described above, with the exception that the $50 \mathrm{ml}$ sampling tubes containing $30 \mathrm{ml}$ of sterile PBS solution and stored at $4^{\circ} \mathrm{C}$ until its processing.

\section{Microbiological procedures}

The sampled tubes from plant rhizospheres were shaken and serially diluted; dilutions $10^{-3}$ and $10^{-5}$ were cultured in solid Luria Broth (LB) and Peptone Yeast (PY) media. The Petri dishes were then incubated $\left(28^{\circ} \mathrm{C}\right)$. Single colonies were isolated, and colony forming units 
(cfu) were estimated from colony counts with averages of $10^{6} \mathrm{cfu}$. Isolated colonies were screened for the following morphological traits: form, border, elevation, surface, consistency, color, transmitted, and reflected light (Supplementary Figure S2). Results from the morphological variables were used as input to a multiple classification analysis (MCA) ordination to select representative colony diversity resulting in the selection of 235 isolates. Each isolate was grown in LB liquid media for 42 . Absorbance was followed at $600 \mathrm{~nm}$ in a Genesys 20 spectrophotometer (Thermo Scientific). Each isolate was classified as slow, medium, and fast grower (Supplementary Figure S3).

\section{Experimental evolution setup}

The 235 representative strains of bacteria morphological diversity were chosen as input for an experimental evolution mesocosm. We denominated this 235 strains subset as the synthetic community (SC). The goal was to assemble a synthetic community capable of tolerating mine tailing heavy metals, use plant-derived or complex carbon sources as main building block for their metabolism, and being capable to establish as a community and thus relationships of mutualism, and competition. Each one of the 235 isolates of the SC was grown until reaching an $\mathrm{OD}_{600} \sim 0.4$ and then $100 \mu \mathrm{L}$ of culture transferred to fresh LB liquid media used all of them as the source for the experimental evolution setup.

We determined the concentration (w/v \%) of the Nacozari mine tailings (Agate mortar ground, 2 rounds of autoclave sterilization) capable of inhibiting growth of two type strains Escherichia coli BW25113 and Pseudomonas koreensis used as controls to discard competition from non-adapted strains; strains were kindly donated by Dr. Luis Servín and Dr. Gloria Soberón both from Instituto de Investigaciones Biomédicas, UNAM. We chose the selecting condition of $16 \%(\mathrm{w} / \mathrm{v})$ mine-tailing as it reduces 1 fold growth when compared to LB media (Supplementary Figure S3). The selection of plant-derived or complex carbon sources (mannitol) was done by using two independent media culture: 1) Soybean (Glycine max) sprouts sterilized homogenate as $\mathrm{C}, \mathrm{N}$, and P sole source; 2) LB media with mannitol $(3 \% \mathrm{w} / \mathrm{v})$ as sole carbon source. There were two independent lines of each culture media, each one with duplicates.

The SC was inoculated into $30 \mathrm{ml}$ of each experimental medium. After SC inoculation, the flask was incubated for $48 \mathrm{~h}\left(28^{\circ} \mathrm{C}, 70 \mathrm{rpm}\right)$, then $1 \mathrm{ml}$ of culture was transferred to fresh 
medium; this procedure was repeated three more times. Then, twenty-two serial passes were performed as described above with the new fresh experimental medium. After the experimental evolution setup, bacterial colonies were re-isolated, and the whole set of isolates was named as the final synthetic community (FSC).

\section{Metagenomic DNA extraction}

Plant roots were vortex-shaked and sonicated on sterile PBS solution, to get the rhizospheric pellet as described elsewhere (Lundberg et al.,2012). The metagenomic DNA was extracted from the pellets with the MoBio ${ }^{\circledR}$ PowerSoil extraction kit (MoBio Laboratories, Solana Beach, CA, USA). For the cultured microbes, individual bacterial colonies from each plant, $\mathrm{SC}$, and FSC were tooth-picked into a $2 \mathrm{ml}$ centrifuge tube for each community containing sterilized water, proteinase K and lysozyme (both from Sigma-Aldrich, St. Louis Missouri, United States) were added for an initial lysis $\left(37^{\circ} \mathrm{C}, 30 \mathrm{~min}\right)$. The tubes were centrifuged and the pellets were used as the source for DNA extraction with the MoBio ${ }^{\circledR}$ PowerSoil extraction kit.

\section{Amplification of the 16S rRNA gene}

The PCR reactions were carried out to amplify the V3-V4 region $(341 \mathrm{~F}$ and 805R primers; 464 bp amplicon; Klindworth 2013) following the Illumina ${ }^{\circledR} \quad$ MiSeq $^{\mathrm{TM}}$ protocol with 5' overhangs. We performed triplicated PCR reactions for each sample, using the high fidelity Pfx platinum polymerase (Invitrogen, Thermo Fisher Scientific Corporation, Carlsbad, California, USA) with following conditions: denaturation at $95{ }^{\circ} \mathrm{C}$ for $3 \mathrm{~min} ; 5$ cycles of denaturation at $94{ }^{\circ} \mathrm{C}$ for $30 \mathrm{~s}$, annealing at $55^{\circ} \mathrm{C}$ for $30 \mathrm{~s}$, and extension at $68{ }^{\circ} \mathrm{C}$ for $30 \mathrm{~s}, 25$ cycles of two-step cycling with denaturation at $94{ }^{\circ} \mathrm{C}$ for $5 \mathrm{~s}$, and extension at $68{ }^{\circ} \mathrm{C}$ for $30 \mathrm{~s}$; final extension at $68{ }^{\circ} \mathrm{C}$ for $5 \mathrm{~min}$. Finally, amplicons from each replicate were pooled and purified with the Wizard SV Gel and PCR Cleanup System kit (Promega Corporation, Madison, Wisconsin, USA).

\section{DNA sequencing}

Amplicons of the 16S rRNA gene were sequenced through Illumina MiSeq 2x250 paired-end technology (Illumina ${ }^{\circledR}$, San Diego, California, USA) at the Unidad de Secuenciación Masiva of the UNAM Biotechnology Institute (Cuernavaca, Morelos, Mexico). The whole shotgun 
metagenomic DNA from the rhizosphere of A. farnesiana growing on mine tailing substrate and the SC were sequenced with Illumina ${ }^{\circledR}$ HiSeq $2000(2 \times 100)$ at Macrogen (Korea). Finally, the shotgun metagenomic DNA of the FSC community was sequenced at the Genomic Services laboratory Unidad de Genómica Avanzada (UGA, formerly LANGEBIOCINVESTAV, Mexico) using Illumina ${ }^{\circledR}$ MiSeq 2x300 technology.

\section{Bioinformatic analyses}

Quality control of the 16S rRNA gene amplicon sequences was performed with FASTXtoolkit v0.0.14 (http://hannonlab.cshl.edu/fastx_toolkit/) and paired reads were merged with PANDAseq v2.11 (Masella et al., 2012). OTUs were built clustering the merged reads at 97\% identity with $c$-hit-est v4.6 (Fu et al., 2012). The QIIME v1.9.1 pipeline (Caporaso et al., 2010) was used to assign taxonomy using the BLAST v2.2.22 algorithm (Camacho et al., 2009) against the Greengenes database (release 13_8; DeSantis et al.,2006) and sequences from chloroplasts and mitochondria were removed. The resulting OTUs table was analyzed with the phyloseq library v1.24.2 (McMurdie \& Holmes, 2013) for R v3.5.1 (www.rproject.org) removing singleton OTUs.

The whole metagenome shotgun (WMS reads) were processed with Trimmomatic v0.33 (Bolger, Lohse, \& Usadel, 2014), keeping sequences with minimum length of 36 nucleotides and a Phred quality $>15$ in sliding windows of 4 nucleotides. Whole shotgun metagenomic taxonomic profile was done using high-quality reads (HQ-reads), then mapped them against the NCBI-nr-protein database with the Kaiju v1.6.2 program (Menzel, Ng \& Krogh, 2016). Additionally, WMS 16S rRNA gene fragments were recovered from the HQ-reads with SSUALIGN v0.1.1 (Nawrocki \& Eddy, 2013) and taxonomy was assigned with BLAST v2.2.22 (Camacho et al., 2009) against the Greengenes database (release 13_8; DeSantis et al.,2006).

HQ-reads of each sample were assembled separately with MEGAHIT v1.1.3 (Li et al., 2016), using minimum kmer size $=21$, maximum kmer size $=141$, $k$ mer increment $=12$, and removing unitigs with average kmer depth $<2$, and the resulting contigs were used to predict ORFs and protein sequences with Prodigal v2.6.3 (Hyatt et al., 2010). Protein sequences were clustered at 90\% identity with CD-HIT v4.7 (Fu et al., 2012) and the representative sequences were annotated against the M5nr database (Wilke et al., 2012) using DIAMOND v0.9.22 (Buchfink, Xie, \& Huson, 2014). An independent annotation was also done using the BlastKOALA server (Kanehisa, Sato \& Morishima, 2016). Unannotated proteins of all 
samples were clustered with CD-HIT v4.7 (Fu et al., 2012) at 70\% identity to add unannotated data to the protein content comparisons. To compare predicted protein content, a protein feature table was built for each metagenome including both the abundance of proteins annotated with the M5nr database and the abundance of unannotated protein families clustered at $70 \%$ identity. The abundance of each protein was assigned through mapping of HQ-reads against predicted ORFs with Bowtie 2 v2.3.4.2 (Langmead, \& Salzberg, 2012). The gene table was inspected using phyloseq v1.24.2 (McMurdie \& Holmes, 2013) for R v3.5.1 (www.r-project.org) through the Subsystems ontology (Overbeek et al., 2005) downloaded from the MG-RAST API (Wilke et al., 2015).

Metagenomic HQ-reads of the FSC dataset were mapped against the Enterobacter sp. SA187 genome (RefSeq accession GCF_001888805.2; Andrés-Barrao, et al.,2017) with Bowtie 2 v2.3.4.2 (Langmead, \& Salzberg, 2012) and read coverage along the reference genome were visualized with CIRCUS v2.7 (Naquin, et al.,2014) and the CGView server (Grant \& Stothard, 2008). To recover genomic sequences, metagenomic contigs of all samples were classified with Kraken v0.10.6 (Wood \& Salzberg, 2014) and assigned contigs from each analyzed genus was mapped to a reference genome downloaded from the NCBI Assembly database using scaffold_builder (Silva et al.,2013), Quast v5.0.0 (Gurevich, et al.,2013), and Mummer v3.0 (Kurtz, et al.,2004). Detailed bioinformatic and statistical protocols are available at: https://github.com/genomica-fciencias-unam/nacozari/

\section{Results}

\section{Selection of a Synthetic Community}

A total of 861 isolates were recovered from the rhizospheres of the pioneer plants growing on the tailing dam at Nacozari de García. The colony morphology classification resulted in 105 unique morphotypes. Through a multivariate morphology analysis (Supplementary Figure 2), the overall colony morphological diversity was evaluated and a subset of 235 isolates was selected to produce up the Synthetic Community (SC). A microcosm experiment was performed, 22 serial passes were carried out in media supplemented with $16 \%(\mathrm{w} / \mathrm{v})$ minetailings, 144 isolates representing 10 morphotypes were recovered from the Final Synthetic Community (FSC) (Figure 1). 


\section{Sequencing of mine tailing and cultured microbial communities}

Environmental rhizosphere microbiomes of plants growing on mine tailings were inspected through the massive sequencing of the 16S rRNA gene to measure the overall in diversity and find out the fraction recovered with our culture-dependent approach. The 16S rRNA gene amplicon sequencing resulted in 2,072,065 raw paired reads, of which $47.76 \%$ were assembled and clustered into 21,851 OTUs (Supplementary Table S1). The mine tailing rhizosphere with the largest number of OTUs was the roots from $\mathrm{Bc}$ with 8,868 , followed closely by Bs with 8,742, while the sample with the lowest number was AfP1 with 3,581. According to the Chaol theoretical estimation of the maximum number of OTUs, the percentage of recovered OTUs ranged between 85.60 (for AfP1) and 95.86 (for AfP2). Similarly, 9,271 filtered OTUs were found in all cultivated community samples ranging from 2,716 for Bc-CCT to 718 for Gl-CCT. The coverage of observed OTUs was highest for GlCCT with $97.81 \%$ and lowest for Bc-CCT with $86.85 \%$.

Three samples were analyzed through whole metagenome shotgun sequencing: the mine tailing rhizosphere of $A$. farnesiana growing on the vegetation patch 1 (Af-MG), the SC, and the FSC. The environmental metagenome Af-MG included 33,354,342 reads spanning $3,368,788,542 \mathrm{bp}$ and the GC\% content was $58.71 \%$. The SC metagenome comprised $36,478,480$ reads adding up to $3,684,326,480$ bp with a GC\% of $62.02 \%$ while the FSC had 20,578,692 reads spanning 6,173,607,600 bp with 59.5 GC\% (Supplementary Table 1).

\section{Changes in diversity from environmental to cultivated microbiomes}

In most samples from mine tailing substrate, the dominant bacterial phylum was Actinobacteria (46.74\%, 39.98\% and 38.22\% for AfP1, Bc, and Bs, respectively) and showed fewer sequences for Proteobacteria, that was the most abundant in AfP2 and G1 (63.78\%, and $37.25 \%$, respectively; Supplementary Table S2). The cultured consortia were all dominated by Proteobacteria $(\underline{x}=\dot{i} 80.06 \%)$ and Actinobacteria to a lesser extent $(\underline{x}=\dot{i} 18.47 \%$; Supplementary Table 3), this loss of diversity was quantified through the Shannon and Simpson indexes of these samples. Both Shannon and Simpson indexes decayed when compared to their uncultured counterparts, for example, the rhizospheric community of $B$. sarothroides had a Shannon diversity index $(\mathrm{H})=7.14$, while the cultivated community had $\mathrm{H}=4.11$ (Figure 2). 


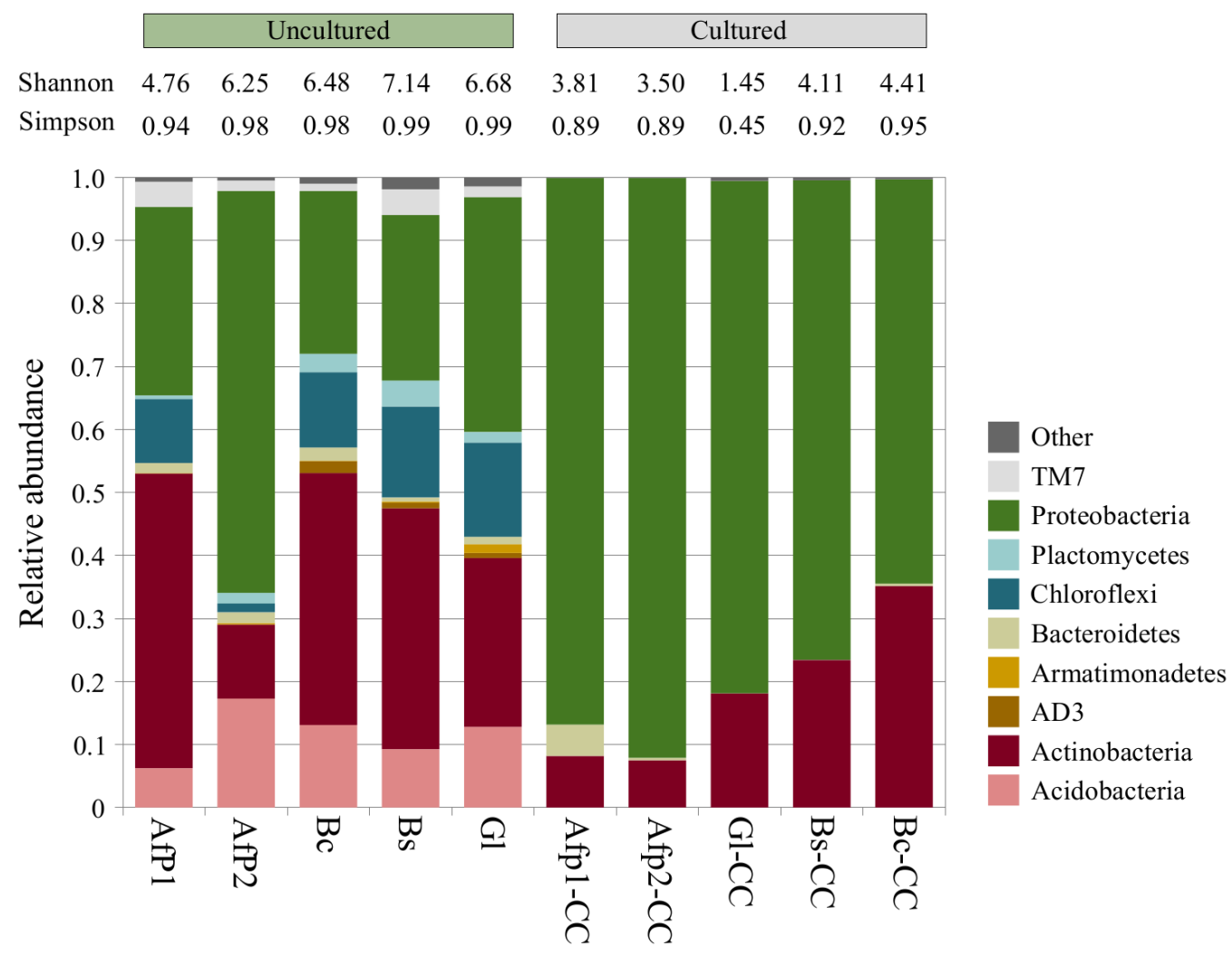

Figure 2. Taxonomic diversity is substantially decreased in the cultured communities, which are dominated by Proteobacteria. Relative frequency of the most abundant phylotypes for $16 \mathrm{~S}$ rRNA gene amplicon sequences. Values for Shannon and Inverse Simpson's diversity indexes for OTU level counts are shown. Af: A. farnesiana; Bc: $B$. coulteri; Bs: B. sarothroides; Gl: G. leucocephalum; -CC: cultivated community.

A total of 94 genera were identified in the SC using only the V3-V4 16S rRNA sequences, sharing 18 genera out of 43 in FSC (Figure 3B, Supplementary Table S4), from which the most frequent were also found in all the plants growing in the tailing vegetation patch, such as Pseudomonas and Ralstonia (17.39 and 9.69\%, respectively). Other abundant genera, like Enterobacter, were only observed in the rhizosphere of some plants such as B. coulteri. The SC also included 10 unique genera, which were all observed at a percentage $<0.03 \%$ of the WMS-reads. Additionally, most HQ-reads (54.34\%) of the FSC were mapped to Enterobacter sequences (Figure 3C; Supplementary Table 5).

Nonbacterial sequences in the metagenomic samples were also found: eukaryotic reads represented the $2.39 \%$ in the Af-MG, $0.14 \%$ in the SC and $0.06 \%$ in the FSC samples. The genera with the highest number of mapped metagenomic reads in all three metagenomes were fungi: Rhizophagus with 14,965 reads in Af-MG (with 54 and 4 reads in the SC and FSC 
metagenomes, respectively); Coniochaeta with 2,600 reads in SC ( 567 and 2 reads in Af-MG and FSC samples, respectively); and Rhizoctonia with 613 reads in FSC (2,641 and 525 reads in Af-MG and SC datasets, respectively). Sequences from the Archaea domain were also found representing $0.24 \%, 0.02 \%$ and $0.005 \%$ of the metagenomic reads in the Af-MG, SC, and FSC samples, respectively. In all samples, the most abundant group was the phylum Euryarchaeota and Halobacteria class (Supplementary Table S5).

A

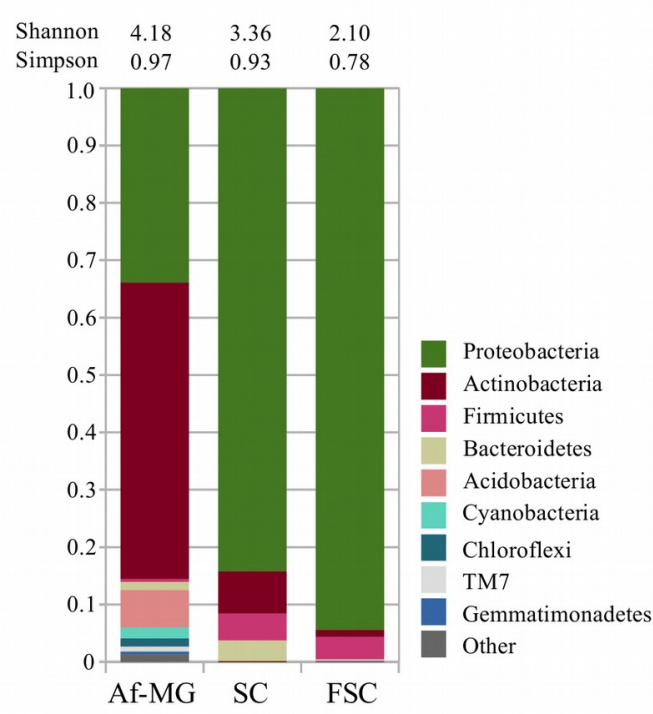

B

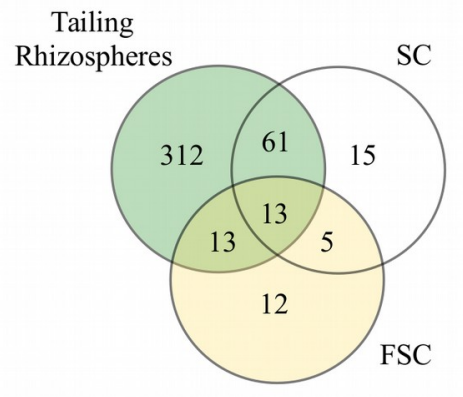

C

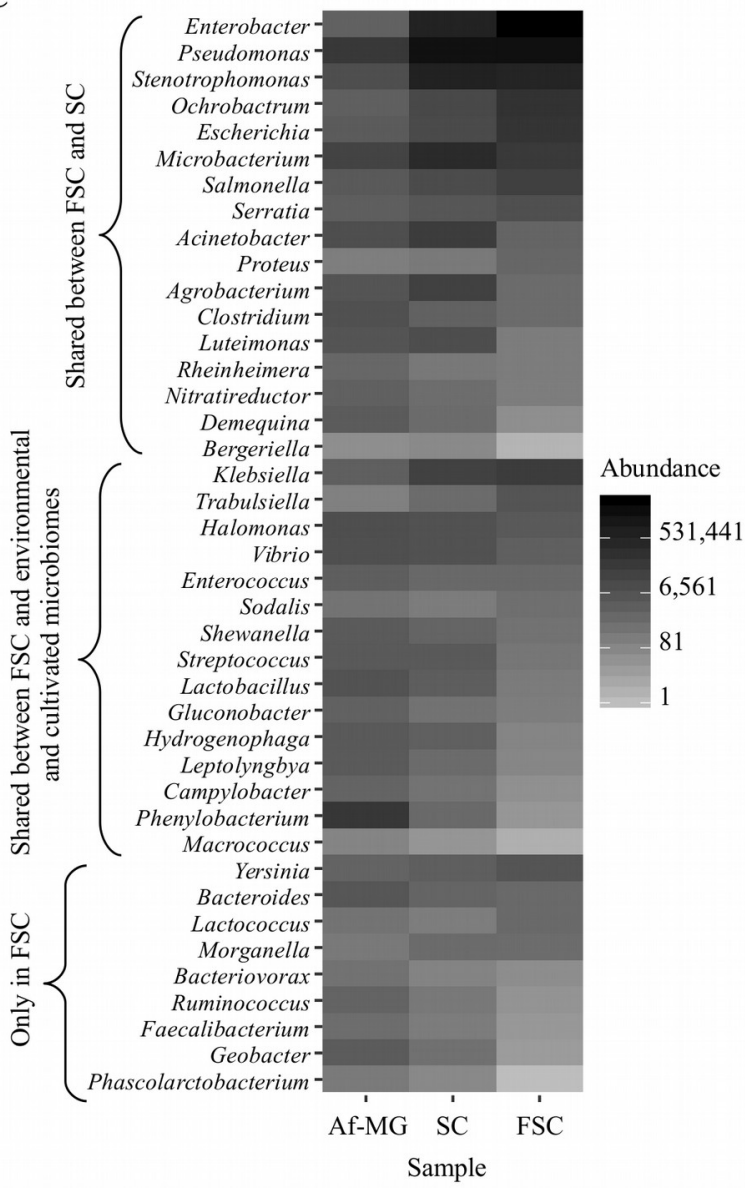

Figure 3. Taxonomic diversity is substantially decreased in the FSC and is dominated by proteobacterial taxa. (A) Relative frequency of bacterial phylotypes of binned 16S rRNA gene (V3-V4) shotgun metagenome sequences from wild samples (Af-MG) and the synthetic communities. (B) Shared genera from 16S rRNA gene assignments, from the 4 rhizospheres of local plants (tailing rhizospheres amplicons), and shotgun fragments binned to V3-V4 region from the synthetic communities. (C) Metagenomic binning and taxonomic placement using translated genes searched in the NCBI NR protein database for the 41 found genera reported for the final synthetic community (FSC). 


\section{Metagenomic profiles differences from environmental to selected cultivated communities}

Predicted protein diversity of the metagenomes was compared through proteins finding homologues in the reference M5nr database, including hypothetical and conserved hypothetical proteins. Additionally we incorporate, the protein sequences clustering $(70 \%$ amino acid identity) of predicted hypothetical proteins without homologue protein matches in the M5nr. The protein diversity was described by the number of observed and shared proteins between wild and synthetic communities, along the protein Shannon diversity index (Figure 4A). A total of 318,157 proteins were found: 225,733 annotated proteins with the M5nr database and 92,424 hypothetical protein clusters. The environmental metagenome AfMG had the highest count of proteins, followed by the SC (with 173,717 and 146,928 proteins, respectively). Interestingly, the SC had a higher Shannon index than the Af-MG metagenome (11.04 and 11.03, respectively). Even though, the FSC presented the lowest observed proteins $(23,196)$ and Shannon index $(8.78)$, it matched the most proteins to the M5nr database (90.78\%), compared with SC (77\%), and the Af-MG (63.35\%).

A core set of 521 proteins were shared between all metagenomes, of which 166 were annotated by homology with the SEED database, including arsenic resistance proteins, metallic cation efflux systems, antibiotic resistance factors like the polymyxin resistance protein ArnT, and carbohydrate ABC transporter proteins (Supplementary Figure S5, Supplementary Table S6). Among these proteins, a probable $\mathrm{Co} / \mathrm{Zn} / \mathrm{Cd}$ efflux system membrane fusion protein was found enriched in the FSC with $5.95 \%$ of mapped reads in comparison with the $3.66 \%$ of reads in the SC metagenome.

Classification with the SEED subsystems ontology revealed enriched categories for the synthetic communities such as membrane transport, amino acid and derivatives, cell wall and capsule, and Iron acquisition and metabolism (Figure 4B). In the stress response, and motility and chemotaxis subsystems, the FSC was the sample with the highest normalized read counts, with $3.68 \%$ and $2.65 \%$ of mapped reads, respectively. Specifically, from the stress response subsystem, the osmoprotectant $\mathrm{ABC}$ transporter YehZYXW (Lang et al.,2015) was most abundant in the FSC metagenome with $0.2 \%$ of mapped reads, while the SC mapped $0.02 \%$ and was absent in the Af-MG metagenome. From the amino acid and derivatives subsystem, proteins involved in amino acid degradation of arginine and ornithine were enriched in the FSC with $1 \%$ mapped reads (against 0.84 and $0.5 \%$ of mapped reads in the 
SC and Af-MG, respectively). The FSC was also enriched in the conjugative transfer $(1.34 \%$ of mapped reads) and $\mathrm{ABC}$ di-peptide transporters (0.87\%), from the membrane transport subsystem, and for enterobactin biosynthesis (0.58\%). The FSC had a high frequency of functions from the miscellaneous subsystem (6.39\% of mapped HQ-reads), including the ACC deaminase (COG2515), as well on the protein-export related proteins from the Clustering-based subsystems. Besides the enriched subsystems, some categories were only observed in the environmental Af-MG metagenome, such as the nitrogen fixation subsystem (including NifH, NifE, NifN, NifW and NifO; Supplementary Figure S6), and other categories were contained in the SC but were lost after the mesocosm experiment, like the coenzyme F420 synthesis subsystem. Similarly, the Indoleacetamide hydrolase (involved in auxin synthesis) was found in the Af-MG and SC metagenomes but was lost after the mesocosm experiment (Supplementary Figure S6).

A

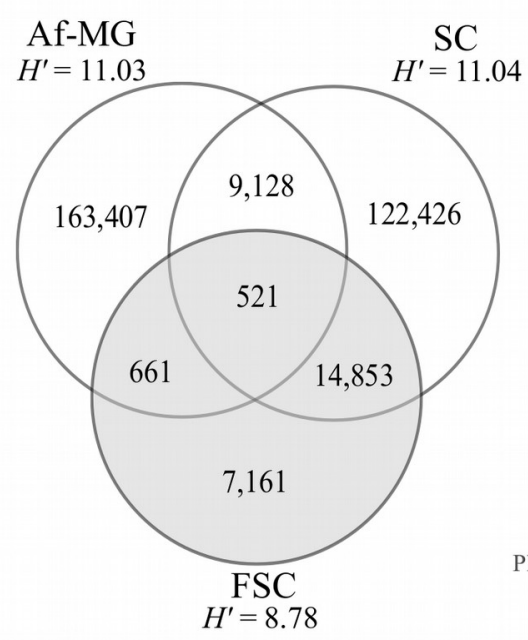

B

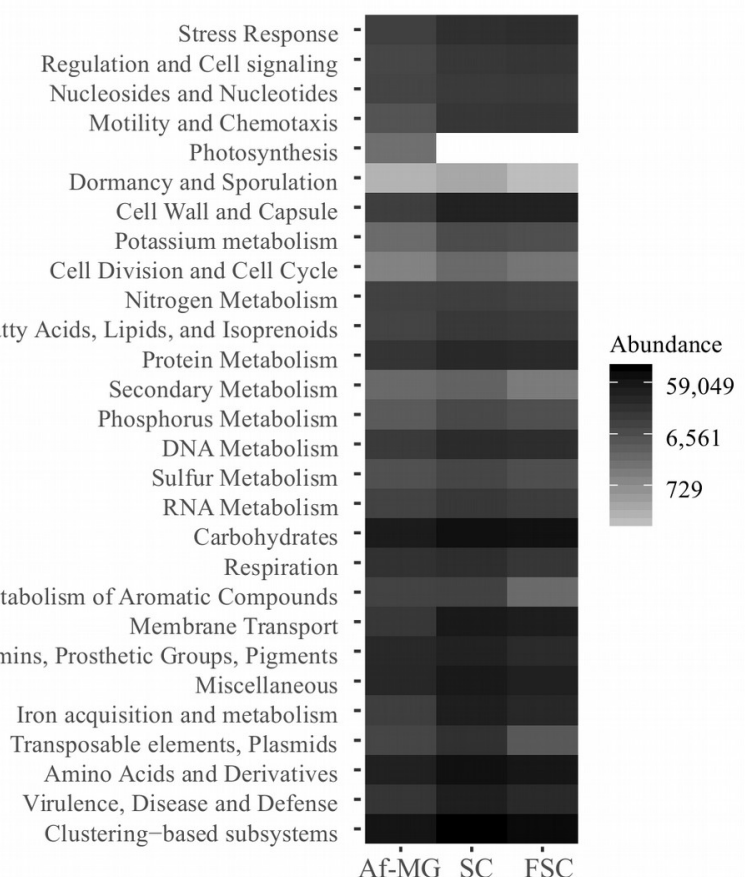

Figure 4. The selected synthetic community (FSC) reduces wild and initial protein diversity and is enriched on subsystems associated with stress response, motility and lacks photosynthesis genes. (A) Total predicted, shared, and unique proteins for wild Acacia farnesiana rhizosphere metagenome (Af-Mg), compared to the protein numbers of the culturable SC and FSC communities. Shannon's protein diversity index $\left(H^{\prime}\right)$ is decreased in the FSC compared to Af-Mg and SC. (B) Metagenomic functional classification showing thousands of reads mapped to genes associated with the first level of SEED Subsystems. 


\section{Genome reconstruction of Enterobacter sp. Nacozari}

Since most (54.34\%) of the mapped metagenomic reads of the FSC mapped against sequences of the Enterobacter sp. and most (37.14\%) of them aligned to Enterobacter sp., SA187 (RefSeq accession GCF_001888805.2; Andrés-Barrao et al., 2017), we used this genome as reference to perform comparative genomics. The new strain was named Enterobacter sp. Nacozari. A total of $93.78 \%$ of the nucleotides of the reference SA187 genome were represented in 7,356,403 of our metagenomic reads (Figure 5A) with a mean sequence identity of $99.1 \%$. Mapped loci included $90.71 \%$ of the coding sequences in the reference SA187. The coding sequences for several plant symbiosis proteins reported in the SA187 genome were mapped, including CsgBAC and CsgDEFG (curli fiber subunits and secretion proteins, respectively; Figure 5B), AcrAB (multidrug efflux pump; Figure 5C) and EntCEBAH (enterobactin biosynthesis; Figure 5D) as well as the siderophore exporter protein EntS. Other plant-symbiosis related proteins such as UbiC (chorismate pyruvatelyase), along with oxidative stress response proteins like SOD1/2 and KatE were included in our sequencing data. Absent loci of the chromosome of Enterobacter sp. SA187 in our metagenomic reads included coding sequences from prophage loci such as the phage tail protein, the phage baseplate assembly protein $\mathrm{V}$, and the phage repressor protein $\mathrm{CI}$ (Supplementary Figure S7). Additionally, the coding loci of the SA187 strain, DndEDCB (DNA sulfur modification) proteins remained unmapped (Supplementary Figure S7).

To recover additional genes that might be present in our assembly but absent in the reference Enterobacter sp., SA187 metagenomic contigs of the three metagenomic samples were classified to get all the Enterobacter assigned sequences. The 344 contigs that were tagged as belonging to the Enterobacter genus represented $80.14 \%$ of the reference genome while the five built scaffolds covered $48.33 \%$ of the reference genome (Supplementary Figure S8; Supplementary Table S7) and had a G-C content of 56.38\%. A total of 5,150 proteins were predicted from these scaffolds and annotation against the KEGG GENES database revealed that the coding sequences belonging to PqqBCDE, pyrroloquinoline quinone biosynthesis proteins were found within this genome fragments (Supplementary Figure S9; Supplementary Table S8). 


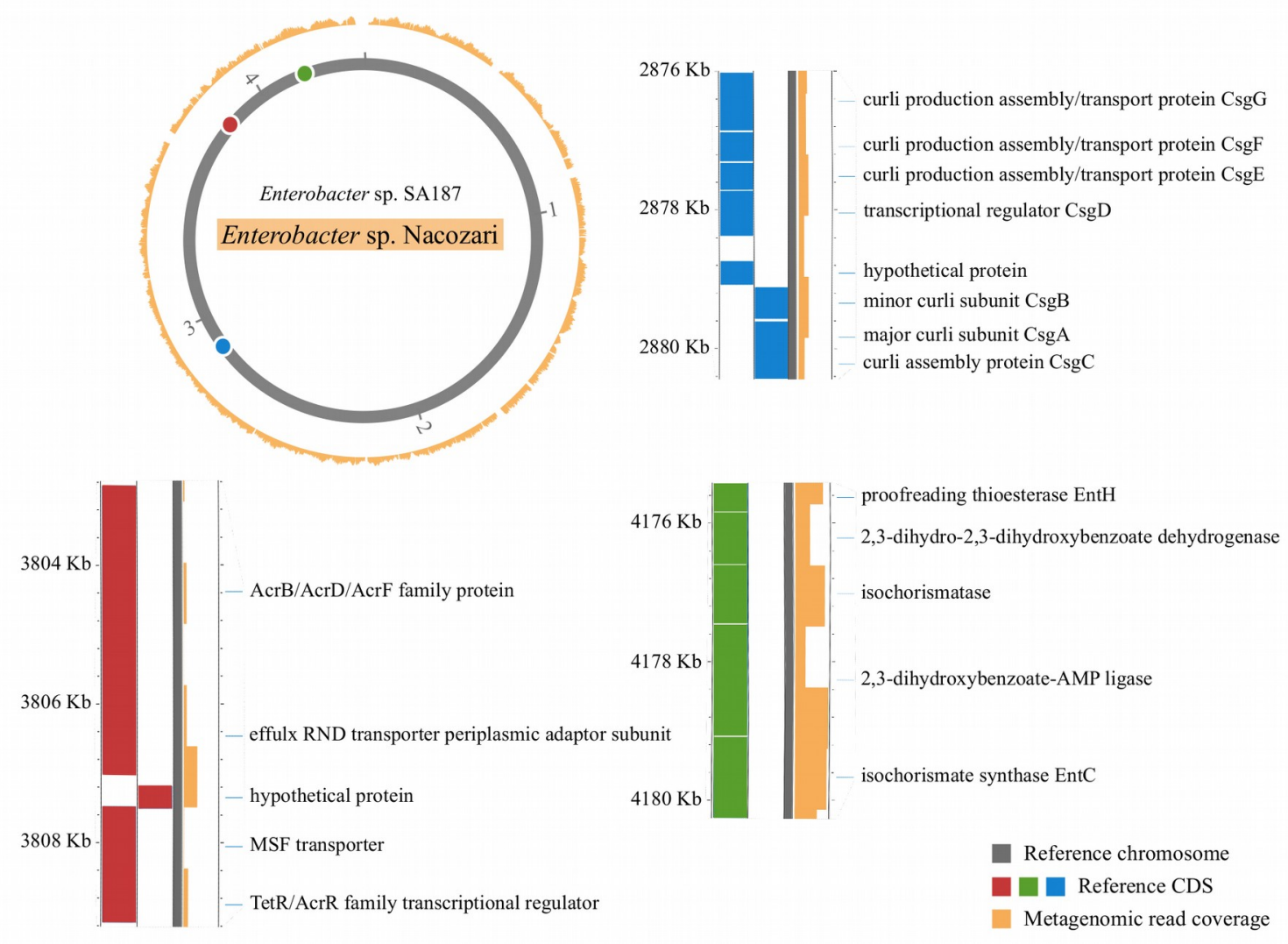

Figure 5. Metagenomic recruitment and assembly of Enterobacter sp. Nacozari against Enterobacter sp. SA187 reference genome, an already described plant-growth promoter bacteria, including described genes associated with plant growth promotion. Enterobacter sp. Nacozari metagenomic sequences (outer yellow ring) aligned to the Enterobacter sp. SA187 genome as a reference (scale in Megabases). Selected loci coverage involved in plan-growth promotion in $E$. sp. SA187 are shown like curli fiber subunits $(\operatorname{csg} B A C)$ and secretion genes $(\operatorname{csg} D E F G)$; the multidrug efflux pump acr $A B$; and the enterobactin biosynthesis entCEBAH.

\section{Discussion}

We are reporting the Nacozari mine tailing rhizospheric culturable and culture-free taxonomic and metabolic diversity. From the culturable organisms, we selected a synthetic microbial community capable of growing on mine tailing substrate, with plant-derived $\mathrm{C}, \mathrm{N}$, and $\mathrm{P}$ sources. While rhizospheric communities had high frequencies of Actinobacteria $(37.99 \%$ on average), as has been observed in our Af-Mg, and arid soils (Crits-Christoph et al., 2013), the SC was dominated by Proteobacteria. Despite other studies have also recovered isolates belonging to Enterobacter, Pseudomonas, and Chryseobacterium from heavy-metal 
contaminated microenvironments (Toribio-Jiménez et al., 2014; Matlakowska \& Sklodowska, 2009). We also isolated bacteria of plant-associated genera like Ralstonia and Burkholderia in high frequency, some Ralstonia species are well-known pathogens of plants (Hayward, 1991), although no canonical pathogenesis factors such as Egl, PehA/B or CbhA were found in our shotgun metagenomic samples, and Burkholderia had been reported as a diazotrophic symbiont (Gillis et al., 1995). Pseudomonas putida, was the reference genome with the most mapped reads in the SC metagenome, it has been found in soil and rhizospheric communities and recent studies comparing several strains have concluded that this bacterial taxon's core-genome lacks virulence factors and can catabolize complex carbon sources, including aromatic compounds (Udaondo et al., 2016). Similarly, in the FSC, most metagenomic reads were mapped to the genome of Enterobacter sp. SA187. This bacterial strain was isolated from the root endosphere of a desert plant and showed plant growth promoting activity (Andrés-Barrao et al., 2017). Furthermore, its genome sequence revealed proteins associated with oxidative stress tolerance, antibiotic production, plant hormone regulation, and adhesion (Andrés-Barrao et al., 2017).

Even though archaeal sequences were observed at low frequencies $(0.24 \%, 0.02 \%$ and $0.005 \%$ of the mapped metagenomic reads in the Af-MG, SC, and FSC samples, respectively), organisms of this kingdom have been observed to be tolerant to heavy metals and might be essential helping other organisms to grow in heavy metal contaminated environments ( $\mathrm{Li}$ et al.,2017). Fungal organisms were represented in the metagenomic samples $(1.59 \%, 0.17 \%$, and $0.04 \%$ of mapped reads in the Af-MG, SC, and FSC samples, respectively) including the Rhizophagus genus, which is a well-known arbuscular mycorrhizal symbiont of plants that has been shown to stimulate plant growth in Acacia holosericea (Duponnois et al., 2005), that was the fungi with most mapped sequences in the Af-MG metagenome but its frequency decreased drastically in the cultured samples with 14,965 reads in Af-MG (0.09\%), 54 in the SC and 4 reads in the FSC metagenome.

We used the Shannon diversity index to describe metabolic diversity, analyzed through matched proteins against the M5nr database and the clustering of unmatched proteins at $70 \%$ sequence identity. Although the ranges of the Shannon index varied, the same pattern was observed: the Af-MG and the SC had similar values while the FSC had a lower value (11.03, 11.04 and 8.78 for Af-MG, SC and FSC, respectively). The metabolic diversity in the SC metagenome, resembling the value of the culture-free Af-MG, may be due to the fact that SC resulted from the combination of several cultured rhizospheric communities, from four plant 
species and that each one carried a specific functional profile which added up to the unexpectedly high number of unique protein features in this sample (Figure 4A). Interestingly, the taxonomic diversity in the $\mathrm{SC}$ was lower (3.36) than the one in the Af-MG sample (4.18). This result is in opposition to previous observations where the functional diversity strongly correlates with the taxonomic diversity (Fierer et al.,2013), and might be a result of similar taxa carrying different genes (i.e. a large pan-genome), as has been observed for the Pseudomonas genus (Hesse et al., 2018), which was present in high frequency in the SC metagenome (17.39\% of mapped reads).

A total of 521 proteins were present in the Af-MG, SC, and FSC, thus being a shared core between environmental metagenomes and cultured ones. The core features proteins that have been reported as heavy metal resistance factors such as the CusA P-type ATPase (Taylor et al.,1988; Gillan et al.,2015) and the As resistance protein ArsH (Chen, Bhattacharjee \& Rosen, 2015; Li et al.,2014). Furthermore, within this core we also found antibiotic resistance genes such as beta-lactamases and the polymyxin resistance protein ArnT which might be essential to withstand the antagonism in these microbial communities, they could also be coselected along with the heavy metal resistance genes (Pal et al., 2015).

The stress response proteins in the FSC included stress response factors which were selected in the harsh conditions of the mesocosm experiment. Among them, we found YehZ, an osmoprotectant transporter found in Enterobacteriaceae that has been upregulated in nutrient starvation, acidic pH, and hyperosmotic stress conditions (Kim, Ryu \& Yoon, 2013). Nutrient acquisition strategies which may be relevant in a plant-host associated environment, were also selected in this system. Such as TonB-dependent receptors which are involved in the uptake of dissolved organic matter, siderophores and vitamins in marine environments (Tang et al.,2012). Likewise, peptide $\mathrm{ABC}$ transporters have also been found enriched in genomes from rhizospheric bacteria (Matilla et al.,2007), and bacterial secretion systems which might be relevant in the bacterial interactions with the plant host and other bacteria (Green \& Mecsas, 2016). Other proteins associated with plant-bacteria symbiosis found in the FSC are siderophore producing enzymes (Kloepper et al.,1980), and the ACC deaminase, which modulates ethylene levels in the plant, thus preventing the negative effects of this plant hormone in stressing conditions (Mayak, Tirosh \& Glick, 2004). This community also harbors galactoglucan biosynthesis enzymes, that are involved in biofilm formation, which might form complexes with the metal ions from the mine tailing substrate and thus preventing their accumulation by the plant (Macaskie \& Dean, 1987). However, other crucial plant 
growth promoting proteins were lost after the synthetic ecology experiment, like the indoleacetamide hydrolase, involved in the synthesis of the plant hormone indole-3-acetic acid (Clark et al., 1993).

The strain Enterobacter sp. SA187 has been described as an endophytic plant growth promoting organism which could stand unfavorable abiotic conditions such as oxidative stress (Andrés-Barrao et al., 2017). Our metagenomic reads mapped to plant symbiosis proteins such as AcrAB, which form an efflux pump involved in plant colonization (Burse, Weingart \& Ullrich et al.,2004); and CsgBAC, that code for the curli fiber subunits that are required during late plant root colonization and might mediate the adhesion of this organism to the plant surface (Cowles et al.,2016). The enterobactin biosynthesis polycistron entCEBAH, recovered from the metagenomic reads of the FSC, have been shown to promote plant growth in heavy metal contaminated soil through the provision of $\mathrm{Fe}$ in the presence of other metals and through the decrease of oxidative stress in the plant due to binding of metals near the roots (Dimkpa et al.,2009). Thus, entCEBAH might be a consistent plant growth promoting factor in mine tailings as siderophores. Besides, the enterobactin exporter EntS has been reported as highly expressed when Enterobacter sp. SA187 was associated with roots of Arabidopsis thaliana (Andrés-Barrao et al., 2017). Indirect plant growth promoting proteins were also included, like UbiC, which is involved in the synthesis of 4-hydroxybenzoate, an antibiotic that has been shown to reduce the rate of infection of $u b i C$-transformed potato plants of the fungal pathogen Phytophthora infestans (Köhle et al.,2003). Additionally, proteins relevant to the mine tailing conditions were also present in these predicted protein sequences, including SOD1/2 and KatE; however, these proteins could also be relevant in plant tissue establishment, as a plant defense mechanism is the production of reactive oxygen species (Keppler, Baker \& Atkinson, 1989).

The metagenomic reconstructed genome, Enterobacter sp. Nacozari, has the metabolic potential to assimilate plant-derived carbohydrates such as mannose, fructose, and starch. A diverse array of monosaccharide and amino acid ABC transporters was also observed, which could be mediating the capture of plant rhizodeposits and have been found enriched in a plant associated P. putida (Matilla et al.,2007). Moreover, we identified several proteins that have been previously described as plant-growth promoting factors such as the PqqBCDE proteins, that contribute to mineral phosphate solubilization in Enterobacter intermedium (Kim et al.,2003). Furthermore, our following work is to test the plant-growth promoting activities of single isolates as well as the whole FSC under greenhouse experiments with plants occurring 
in the Nacozari mine tailings.

\section{Conclusion}

The taxonomic profile of the mine tailing rhizosphere communities shifted from the environmental dominance of Actinobacteria to Proteobacteria in the cultivated consortia, while a decreasing diversity gradient was observed from the environmental microbiomes to the FSC. In general, the metabolic potential of the selected microbial community (FSC) was enriched in genes related to membrane transport, amino acid metabolism, and iron acquisition in comparison with the Af-MG environmental metagenome and was enriched in motility and stress response subsystems in comparison with the initial synthetic community. A core of genes shared by the environmental and cultivated metagenomes included heavy metal homeostasis related proteins and antibiotic resistance enzymes that could be the result of selective constraints within the mine-tailing. The FSC harbored functions related to plantgrowth promotion such as siderophore production and genes coding for plant hormone synthesis. Finally, we assembled the metagenome-derived genome of the Enterobacter sp. Nacozari, in which we found direct and indirect plant-growth promotion predicted coding genes. The metabolic potential of the FSC presents promising features that might make it useful for plant-growth promotion in a phytostabilization strategies. Further work is in progress to evaluate the plant-growth promotion of the FSC.

\section{Data availability}

The whole metagenomic reads area available in the DDBJ/EMBL/Genbank databases under Bioproject accession: PRJNA525709; BioSample accessions: SAMN11174940, SAMN11174941, SAMN11174942, SAMN11174943, SAMN11174944, SAMN11174945, SAMN11174946, SAMN11174947, SAMN11174948, SAMN11174949, SAMN11174950, SAMN11174951, and SAMN11174952. Detailed bioinformatic and statistical protocols are available at: https://github.com/genomica-fciencias-unam/nacozari/

\section{Funding}

This work was supported by DGAPA-PAPIIT-UNAM TA200117 and Consejo Nacional de 
Ciencia y Tecnología (CONACyT) Ciencia Básica 237387 to LDA, DGAPA-PAPIIT-UNAM IN209015 and UNAM-UA Consortium on Drylands Research to FMF, and DGAPA-PAPIITUNAM IN207418 (RN207418) to RCO. This work was supported by the Posgrado en Ciencias Biológicas, UNAM, in the context of the first author's doctoral studies. MR received a scholarship from the CONACyT.

\section{Acknowledgments}

We thank Dr. Julio Campo at Instituto de Ecología, Universidad Nacional Autónoma de México (IE-UNAM) for his assistance processing mine tailing material. Rodrigo García Herrera, head of the Scientific Computing Department at LANCIS-IE-UNAM, for running the HTC infrastructure used for the analyses. MR is a student from the Posgrado en Ciencias Biológicas, Universidad Nacional Autónoma de México (UNAM) and received fellowship 692969 from CONACyT.

\section{Conflict of Interest Statement}

The authors declare there are no conflicts of interests including any commercial or financial relationships.

\section{Author Contributions}

LDA, DG, MP, RCO, and FMF conceived and designed the experiments. Field sampling, and laboratory work was coordinated and executed by: DG, MR, JB, AL, JMF, HB, CHK, RCO, FMF, LDA. DG carried out the microbiology/mesocosm experiment. Bioinformatic and statistical analysis was performed by MR, DG, JB, AL, LDA. Contributed reagents/materials/analysis tools: FMF, MP, RCO, LDA. MR and LDA were responsible for primary manuscript elaboration and merging input from all the authors. MR, DG, MP, and LDA contributed to figure elaboration. 


\section{References}

Ali, H., Khan, E., \& Sajad, M. A. (2013). Phytoremediation of heavy metals-Concepts and applications. Chemosphere, 91(7), 869-881. https://doi.org/10.1016/j.chemosphere.2013.01.075

Andrés-Barrao, C., Lafi, F. F., Alam, I., de Zélicourt, A., Eida, A. A., Bokhari, A., ... Saad, M. M. (2017). Complete Genome Sequence Analysis of Enterobacter sp. SA187, a Plant Multi-Stress Tolerance Promoting Endophytic Bacterium. Frontiers in Microbiology, 8, 2023. https://doi.org/10.3389/fmicb.2017.02023

Bhardwaj, D., Ansari, M. W., Sahoo, R. K., \& Tuteja, N. (2014). Biofertilizers function as key player in sustainable agriculture by improving soil fertility, plant tolerance and crop productivity. Microbial Cell Factories, 13, 66. https://doi.org/10.1186/14752859-13-66

Bolger, A. M., Lohse, M., \& Usadel, B. (2014). Trimmomatic: a flexible trimmer for Illumina sequence data. Bioinformatics, 30(15), 2114-2120. https://doi.org/10.1093/bioinformatics/btu170

Buchfink, B., Xie, C., \& Huson, D. H. (2015). Fast and sensitive protein alignment using DIAMOND. Nature Methods, 12(1), 59-60. https://doi.org/10.1038/nmeth.3176

Bulgarelli, D., Schlaeppi, K., Spaepen, S., van Themaat, E. V. L., \& Schulze-Lefert, P. (2013). Structure and Functions of the Bacterial Microbiota of Plants. Annual Review of Plant Biology, 64(1), 807-838. https://doi.org/10.1146/annurev-arplant-050312120106

Burse, A., Weingart, H., \& Ullrich, M. S. (2004). The phytoalexin-inducible multidrug efflux pump AcrAB contributes to virulence in the fire blight pathogen, Erwinia amylovora. Molecular Plant-Microbe Interactions : MPMI, 17(1), 43-54. https://doi.org/10.1094/MPMI.2004.17.1.43

Cairns, J., Jokela, R., Hultman, J., Tamminen, M., Virta, M., \& Hiltunen, T. (2018). Construction and Characterization of Synthetic Bacterial Community for Experimental Ecology and Evolution. Frontiers in Genetics, 9, 312. https://doi.org/10.3389/fgene.2018.00312

Camacho, C., Coulouris, G., Avagyan, V., Ma, N., Papadopoulos, J., Bealer, K., \& Madden, T. L. (2009). BLAST+: Architecture and applications. BMC Bioinformatics, 10, 421. https://doi.org/10.1186/1471-2105-10-421 
Caporaso, J. G., Kuczynski, J., Stombaugh, J., Bittinger, K., Bushman, F. D., Costello, E. K., ... Knight, R. (2010). QIIME allows analysis of high-throughput community sequencing data. Nature Methods, 7(5), 335-336. https://doi.org/10.1038/nmeth.f.303

Chen, J., Bhattacharjee, H., \& Rosen, B. P. (2015). ArsH is an organoarsenical oxidase that confers resistance to trivalent forms of the herbicide monosodium methylarsenate and the poultry growth promoter roxarsone. Molecular Microbiology, 96(5), 1042-1052. https://doi.org/10.1111/mmi.12988

Clark, E., Manulis, S., Ophir, Y., Barash, I., \& Gafni, Y. (2007). Cloning and Characterization of iaaM and iaaH from Erwinia herbicola pathovar gypsophilae. Phytopathology. https://doi.org/10.1094/phyto-83-234

Cowles, K. N., Willis, D. K., Engel, T. N., Jones, J. B., \& Barak, J. D. (2016). Diguanylate cyclases AdrA and STM1987 regulate Salmonella enterica exopolysaccharide production during plant colonization in an environment-dependent manner. Applied and Environmental Microbiology. https://doi.org/10.1128/AEM.03475-15

Crits-Christoph, A., Robinson, C. K., Barnum, T., Fricke, W., Davila, A. F., Jedynak, B., ... DiRuggiero, J. (2013). Colonization patterns of soil microbial communities in the Atacama Desert. Microbiome, 1(1), 28. https://doi.org/10.1186/2049-2618-1-28

de Zélicourt, A., Synek, L., Saad, M. M., Alzubaidy, H., Jalal, R., Xie, Y., ... Hirt, H. (2018). Ethylene induced plant stress tolerance by Enterobacter sp. SA187 is mediated by 2keto-4-methylthiobutyric acid production. PLOS Genetics, 14(3), e1007273. https://doi.org/10.1371/journal.pgen.1007273

DeSantis, T. Z., Hugenholtz, P., Larsen, N., Rojas, M., Brodie, E. L., Keller, K., ... Andersen, G. L. (2006). Greengenes, a chimera-checked 16S rRNA gene database and workbench compatible with ARB. Applied and Environmental Microbiology, 72(7), 5069-72. https://doi.org/10.1128/AEM.03006-05

Dimkpa, C. O., Merten, D., Svatoš, A., Büchel, G., \& Kothe, E. (2009). Metal-induced oxidative stress impacting plant growth in contaminated soil is alleviated by microbial siderophores. Soil Biology and Biochemistry. https://doi.org/10.1016/j.soilbio.2008.10.010

Duponnois, R., Colombet, A., Hien, V., \& Thioulouse, J. (2005). The mycorrhizal fungus Glomus intraradices and rock phosphate amendment influence plant growth and microbial activity in the rhizosphere of Acacia holosericea. Soil Biology and Biochemistry. https://doi.org/10.1016/j.soilbio.2004.09.016

Favas, P. J. C., Martino, L. E., \& Prasad, M. N. V. (2018). Abandoned Mine Land Reclamation-Challenges and Opportunities (Holistic Approach). In Bio- 
Geotechnologies for Mine Site Rehabilitation (pp. 3-31). Elsevier. https://doi.org/10.1016/B978-0-12-812986-9.00001-4

Fierer, N., Ladau, J., Clemente, J. C., Leff, J. W., Owens, S. M., Pollard, K. S., .. McCulley, R. L. (2013). Reconstructing the microbial diversity and function of pre-agricultural tallgrass prairie soils in the United States. Science. https://doi.org/10.1126/science. 1243768

Fu, L., Niu, B., Zhu, Z., Wu, S., \& Li, W. (2012). CD-HIT: accelerated for clustering the next-generation sequencing data. Bioinformatics (Oxford, England), 28(23), 31503152. https://doi.org/10.1093/bioinformatics/bts565

Gillan, D. C., Roosa, S., Kunath, B., Billon, G., \& Wattiez, R. (2015). The long-term adaptation of bacterial communities in metal-contaminated sediments: a metaproteogenomic study. Environmental Microbiology, 17(6), 1991-2005. https://doi.org/10.1111/1462-2920.12627

Gillis, M., Bardin, R., Goor, M., Hebbar, P., Willems, A., Segers, P., ... Fernandez3, M. P. (1995). Polyphasic taxonomy in the genus Burkholderia leading to an emended description of the genus and proposition of Burkholderia vietnamiensis sp. nov. for N2-fixing isolates from rice in Vietnam. Internation Journal of Systematic Bacteriology.

Glick, B. R., Penrose, D. M., \& Li, J. (1998). A model for the lowering of plant ethylene concentrations by plant growth-promoting bacteria. Journal of Theoretical Biology, 190(1), 63-68. https://doi.org/10.1006/jtbi.1997.0532

Good, B. H., McDonald, M. J., Barrick, J. E., Lenski, R. E., \& Desai, M. M. (2017). The dynamics of molecular evolution over 60,000 generations. Nature, 551(7678), 45-50. https://doi.org/10.1038/nature24287

Grant, J. R., \& Stothard, P. (2008). The CGView Server: a comparative genomics tool for circular genomes. Nucleic Acids Research. https://doi.org/10.1093/nar/gkn179

Green, E. R., \& Mecsas, J. (2016). Bacterial Secretion Systems: An Overview. In Virulence Mechanisms of Bacterial Pathogens, Fifth Edition (Vol. 4, pp. 215-239). American Society of Microbiology. https://doi.org/10.1128/microbiolspec.VMBF-0012-2015

Gurevich, A., Saveliev, V., Vyahhi, N., \& Tesler, G. (2013). QUAST: quality assessment tool for genome assemblies. Bioinformatics, 29(8), 1072-1075. https://doi.org/10.1093/bioinformatics/btt086

Hayward, A. C. (1991). Biology and Epidemiology of Bacterial Wilt Caused by Pseudomonas solanacearum. Annual Review of Phytopathology, 29(1), 65-87. https://doi.org/10.1146/annurev.py.29.090191.000433 
Herrera Paredes, S., Gao, T., Law, T. F., Finkel, O. M., Mucyn, T., Teixeira, P. J. P. L., ... Castrillo, G. (2018). Design of synthetic bacterial communities for predictable plant phenotypes. PLOS Biology, 16(2), e2003962. https://doi.org/10.1371/journal.pbio.2003962

Hesse, C., Schulz, F., Bull, C. T., Shaffer, B. T., Yan, Q., Shapiro, N., ... Loper, J. E. (2018). Genome-based evolutionary history of Pseudomonas spp. Environmental Microbiology, 20(6), 2142-2159. https://doi.org/10.1111/1462-2920.14130

Hyatt, D., Chen, G.-L., Locascio, P. F., Land, M. L., Larimer, F. W., \& Hauser, L. J. (2010). Prodigal: prokaryotic gene recognition and translation initiation site identification. BMC Bioinformatics, 11(1), 119. https://doi.org/10.1186/1471-2105-11-119

Kanehisa, M., Sato, Y., \& Morishima, K. (2016). BlastKOALA and GhostKOALA: KEGG Tools for Functional Characterization of Genome and Metagenome Sequences. Journal of Molecular Biology, 428(4), 726-731. https://doi.org/10.1016/j.jmb.2015.11.006

Keppler, L. D., Baker, C. J., \& Atkinson, M. M. (2007). Active Oxygen Production During a Bacteria-Induced Hypersensitive Reaction in Tobacco Suspension Cells. Phytopathology. https://doi.org/10.1094/phyto-79-974

Kim, S. I., Ryu, S., \& Yoon, H. (2013). Roles of YehZ, a putative osmoprotectant transporter, in tempering growth of Salmonella enterica serovar Typhimurium. Journal of Microbiology and Biotechnology, 23(11), 1560-1568. Retrieved from http://www.ncbi.nlm.nih.gov/pubmed/23966021

Klindworth, A., Pruesse, E., Schweer, T., Peplies, J., Quast, C., Horn, M., \& Glöckner, F. O. (2013). Evaluation of general 16S ribosomal RNA gene PCR primers for classical and next-generation sequencing-based diversity studies. Nucleic Acids Research, 41(1), e1. https://doi.org/10.1093/nar/gks808

Kloepper, J. W., Leong, J., Teintze, M., \& Schroth, M. N. (1980). Enhanced plant growth by siderophores produced by plant growth-promoting rhizobacteria. Nature. https://doi.org/10.1038/286885a0

Köhle, A., Sommer, S., Li, S. M., Schilde-Rentschler, L., Ninnemann, H., \& Heide, L. (2003). Secondary metabolites in transgenic tobacco and potato: High accumulation of 4-hydroxybenzoic acid glucosides results from high expression of the bacterial gene ubiC. Molecular Breeding. https://doi.org/10.1023/A:1022211521390

Kurtz, S., Phillippy, A., ... A. D.-G., 2004, U., Delcher, A. L., Smoot, M., ... Salzberg, S. L. (2004). Versatile and open software for comparing large genomes. Genome Biology. https://doi.org/10.1186/gb-2004-5-2-r12 
Lang, S., Cressatti, M., Mendoza, K. E., Coumoundouros, C. N., Plater, S. M., Culham, D. E., ... Wood, J. M. (2015). YehZYXW of Escherichia coli Is a Low-Affinity, NonOsmoregulatory Betaine-Specific ABC Transporter. Biochemistry, 54(37), 57355747. https://doi.org/10.1021/acs.biochem.5b00274

Langmead, B., \& Salzberg, S. L. (2012). Fast gapped-read alignment with Bowtie 2. Nature Methods, 9(4), 357-359. https://doi.org/10.1038/nmeth.1923

Lenski, R. E., \& Travisano, M. (1994). Dynamics of adaptation and diversification: a 10,000generation experiment with bacterial populations. Proceedings of the National Academy of Sciences of the United States of America, 91(15), 6808-6814. https://doi.org/10.1073/pnas.91.15.6808

Li, D., Luo, R., Liu, C.-M., Leung, C.-M., Ting, H.-F., Sadakane, K., ... Lam, T.-W. (2016). MEGAHIT v1.0: A fast and scalable metagenome assembler driven by advanced methodologies and community practices. Methods (San Diego, Calif.), 102, 3-11. https://doi.org/10.1016/j.ymeth.2016.02.020

Li, L.-G., Cai, L., Zhang, X.-X., \& Zhang, T. (2014). Potentially novel copper resistance genes in copper-enriched activated sludge revealed by metagenomic analysis. Applied Microbiology and Biotechnology, 98(24), 10255-10266. https://doi.org/10.1007/s00253-014-5939-5

Li, X., Meng, D., Li, J., Yin, H., Liu, H., Liu, X., ... Yan, M. (2017). Response of soil microbial communities and microbial interactions to long-term heavy metal contamination. Environmental Pollution. https://doi.org/10.1016/j.envpol.2017.08.057

Liu, S. T., Lee, L. Y., Tai, C. Y., Hung, C. H., Chang, Y. S., Wolfram, J. H., ... Goldstein, A. H. (1992). Cloning of an Erwinia herbicola gene necessary for gluconic acid production and enhanced mineral phosphate solubilization in Escherichia coli HB101: nucleotide sequence and probable involvement in biosynthesis of the coenzyme pyrroloquinoline quinone. Journal of Bacteriology, 174(18), 5814-5819. Retrieved from http://www.ncbi.nlm.nih.gov/pubmed/1325965

Lundberg, D. S., Lebeis, S. L., Paredes, S. H., Yourstone, S., Gehring, J., Malfatti, S., ... Dangl, J. L. (2012). Defining the core Arabidopsis thaliana root microbiome. Nature, 488(7409), 86-90. https://doi.org/10.1038/nature11237

Macaskie, L. E., \& Dean, A. C. R. (1987). Use of immobilized biofilm of Citrobacter sp. for the removal of uranium and lead from aqueous flows. Enzyme and Microbial Technology. https://doi.org/10.1016/0141-0229(87)90042-1

Madsen, J. S., Sørensen, S. J., \& Burmølle, M. (2018). Bacterial social interactions and the emergence of community-intrinsic properties. Current Opinion in Microbiology, 42, 
104-109. https://doi.org/10.1016/j.mib.2017.11.018

Mansotra, P., Sharma, P., \& Sharma, S. (2015). Bioaugmentation of Mesorhizobium cicer, Pseudomonas spp. and Piriformospora indica for Sustainable Chickpea Production. Physiology and Molecular Biology of Plants, 21(3), 385-393. https://doi.org/10.1007/s12298-015-0296-0

Masella, A. P., Bartram, A. K., Truszkowski, J. M., Brown, D. G., \& Neufeld, J. D. (2012). PANDAseq: paired-end assembler for illumina sequences. BMC Bioinformatics, 13(1), 31. https://doi.org/10.1186/1471-2105-13-31

Matilla, M. A., Espinosa-Urgel, M., Rodríguez-Herva, J. J., Ramos, J. L., \& RamosGonzález, M. I. (2007). Genomic analysis reveals the major driving forces of bacterial life in the rhizosphere. Genome Biology, 8(9), R179. https://doi.org/10.1186/gb-20078-9-r179

Matlakowska, R., \& Sklodowska, A. (2009). The culturable bacteria isolated from organicrich black shale potentially useful in biometallurgical procedures. Journal of Applied Microbiology, 107(3), 858-866. https://doi.org/10.1111/j.1365-2672.2009.04261.x

Mayak, S., Tirosh, T., \& Glick, B. R. (2004). Plant growth-promoting bacteria that confer resistance to water stress in tomatoes and peppers. Plant Science. https://doi.org/10.1016/j.plantsci.2003.10.025

McMurdie, P. J., \& Holmes, S. (2013). phyloseq: An R Package for Reproducible Interactive Analysis and Graphics of Microbiome Census Data. PLoS ONE, 8(4), e61217. https://doi.org/10.1371/journal.pone.0061217

Mendez, M. O., \& Maier, R. M. (2008). Phytostabilization of Mine Tailings in Arid and Semiarid Environments-An Emerging Remediation Technology. Environmental Health Perspectives, 116(3), 278-283. https://doi.org/10.1289/ehp.10608

Menzel, P., Ng, K. L., \& Krogh, A. (2016). Fast and sensitive taxonomic classification for metagenomics with Kaiju. Nature Communications, 7(1), 11257. https://doi.org/10.1038/ncomms11257

Meza-Figueroa, D., Maier, R. M., de la O-Villanueva, M., Gómez-Alvarez, A., MorenoZazueta, A., Rivera, J., ... Palafox-Reyes, J. (2009). The impact of unconfined mine tailings in residential areas from a mining town in a semi-arid environment: Nacozari, Sonora, Mexico. Chemosphere, 140-7. https://doi.org/10.1016/j.chemosphere.2009.04.068

Naquin, D., d'Aubenton-Carafa, Y., Thermes, C., \& Silvain, M. (2014). CIRCUS: A package for Circos display of structural genome variations from paired-end and mate-pair sequencing data. BMC Bioinformatics. https://doi.org/10.1186/1471-2105-15-198 
Nawrocki, E. P., \& Eddy, S. R. (2013). Infernal 1.1: 100-fold faster RNA homology searches. Bioinformatics (Oxford, 29(22), 2933-2935. https://doi.org/10.1093/bioinformatics/btt509

Nies, D. H. (1999). Microbial heavy-metal resistance. Applied Microbiology and Biotechnology, 51(6), 730-750. $\quad$ Retrieved from http://www.ncbi.nlm.nih.gov/pubmed/10422221

Nriagu, J. O. (1988). A silent epidemic of environmental metal poisoning? Environmental Pollution (Barking, Essex : 1987), 50(1-2), 139-61. Retrieved from http://www.ncbi.nlm.nih.gov/pubmed/15092656

Overbeek, R., Begley, T., Butler, R. M., Choudhuri, J. V, Chuang, H.-Y., Cohoon, M., ... Vonstein, V. (2005). The subsystems approach to genome annotation and its use in the project to annotate 1000 genomes. Nucleic Acids Research, 33(17), 5691-702. https://doi.org/10.1093/nar/gki866

Pal, C., Bengtsson-Palme, J., Kristiansson, E., \& Larsson, D. G. J. (2015). Co-occurrence of resistance genes to antibiotics, biocides and metals reveals novel insights into their co-selection potential. BMC Genomics, 16(1), 964. https://doi.org/10.1186/s12864015-2153-5

Pérez-Gutiérrez, R. A., López-Ramírez, V., Islas, Á., Alcaraz, L. D., Hernández-González, I., Olivera, B. C. L., ... Olmedo-Alvarez, G. (2013). Antagonism influences assembly of a Bacillus guild in a local community and is depicted as a food-chain network. ISME Journal, 7(3), 487-497. https://doi.org/10.1038/ismej.2012.119

Rodriguez, E., Han, Y., \& Lei, X. G. (1999). Cloning, Sequencing, and Expression of an Escherichia coli Acid Phosphatase/Phytase Gene (appA2) Isolated from Pig Colon. Biochemical and Biophysical Research Communications, 257(1), 117-123. https://doi.org/10.1006/bbrc.1999.0361

Romero, F. M., Armienta, M. A., Gutiérrez, M. E., \& Villaseñor, G. (2008). Factores geológicos y climáticos que determinan la peligrosidad y el impacto ambiental de jales mineros. Revista Internacional de Contaminación Ambiental.

Santos, A. E., Cruz-Ortega, R., Meza-Figueroa, D., Romero, F. M., Sanchez-Escalante, J. J., Maier, R. M., ... Molina Freaner, F. E. (2017). Plants from the abandoned Nacozari mine tailings: evaluation of their phytostabilization potential. PeerJ, 5, e3280. https://doi.org/10.7717/peerj.3280

Silva, G. G. Z., Dutilh, B. E., Matthews, T. D., Elkins, K., Schmieder, R., Dinsdale, E. A., \& Edwards, R. A. (2013). Combining de novo and reference-guided assembly with scaffold_builder. Source Code for Biology and Medicine. 
https://doi.org/10.1186/1751-0473-8-23

Spaepen, S., Versées, W., Gocke, D., Pohl, M., Steyaert, J., \& Vanderleyden, J. (2007). Characterization of phenylpyruvate decarboxylase, involved in auxin production of Azospirillum brasilense. Journal of Bacteriology, 189(21), 7626-7633. https://doi.org/10.1128/JB.00830-07

Tang, K., Jiao, N., Liu, K., Zhang, Y., \& Li, S. (2012). Distribution and functions of TonBdependent transporters in marine bacteria and environments: implications for dissolved organic matter utilization. PloS One, 7(7), e41204. https://doi.org/10.1371/journal.pone.0041204

Taylor, D. E., Walter, E. G., Sherburne, R., \& Bazett-Jones, D. P. (1988). Structure and location of tellurium deposited in Escherichia coli cells harbouring tellurite resistance plasmids. Journal of Ultrastructure and Molecular Structure Research, 99(1), 18-26. Retrieved from http://www.ncbi.nlm.nih.gov/pubmed/3042886

Toribio-Jim\&enez, J., Rodr\&iguez-Barrera, M. \&Angel, Lucena, M. V., Flores, A. B., Segura, D., Wilson-Corral, V., ... Romero*, Y. (2014). Production of biosurfactants by bacteria isolated from a mine tailing zone in Southern Mexico and their resistance to heavy metals. African Journal of Bacteriology Research. https://doi.org/10.5897/jbr2014.0128

Udaondo, Z., Molina, L., Segura, A., Duque, E., \& Ramos, J. L. (2016). Analysis of the core genome and pangenome of Pseudomonas putida. Environmental Microbiology, 18(10), 3268-3283. https://doi.org/10.1111/1462-2920.13015

Valls, M., \& de Lorenzo, V. (2002). Exploiting the genetic and biochemical capacities of bacteria for the remediation of heavy metal pollution. FEMS Microbiology Reviews, 26(4), 327-338. https://doi.org/10.1111/j.1574-6976.2002.tb00618.x

Wilke, A., Bischof, J., Harrison, T., Brettin, T., D’Souza, M., Gerlach, W., ... Meyer, F. (2015). A RESTful API for accessing microbial community data for MG-RAST. PLoS Computational Biology, e1004008. https://doi.org/10.1371/journal.pcbi.1004008

Wilke, A., Harrison, T., Wilkening, J., Field, D., Glass, E. M., Kyrpides, N., ... Meyer, F. (2012). The M5nr: a novel non-redundant database containing protein sequences and annotations from multiple sources and associated tools. BMC Bioinformatics, 13, 141. https://doi.org/10.1186/1471-2105-13-141

Wood, D. E., \& Salzberg, S. L. (2014). Kraken: ultrafast metagenomic sequence classification using exact alignments. Genome Biology, 15(3), R46. https://doi.org/10.1186/gb-2014-15-3-r46 
bioRxiv preprint doi: https://doi.org/10.1101/664805; this version posted June 11,2019 . The copyright holder for this preprint (which was

not certified by peer review) is the author/funder, who has granted bioRxiv a license to display the preprint in perpetuity. It is made available under aCC-BY-NC-ND 4.0 International license.

Zomorrodi, A. R., \& Segrè, D. (2016). Synthetic Ecology of Microbes: Mathematical Models and Applications. Journal of Molecular Biology, 428(5), 837-861. https://doi.org/10.1016/J.JMB.2015.10.019 